S. Gnanasekaran*, G. Padmanaban, V. Balasubramanian, Hemant Kumar and Shaju K. Albert

\title{
Correlation between Travel Speed, Microstructure, Mechanical Properties and Wear Characteristics of Ni-Based Hardfaced Deposits over 316LN Austenitic Stainless Steel
}

https://doi.org/10.1515/htmp-2017-0176

Received November 26, 2017; accepted April 08, 2018

Abstract: Laser hardfacing were produced using a high power Disk laser of $4 \mathrm{~kW}$ maximum power as a heat source to melt and bond the Colmonoy- 5 powder on to AISI 316 LN stainless steel substrate. Significant difference in melting points between the austenitic stainless steel (ASS) substrate and Ni-based Colmonoy alloy results in substantial dilution of the hardfaced deposit from the substrate. In this present study, the effect of travel speed (TS) on microstructure, microhardness and wear characteristics laser hardfaced deposits were investigated. The phase constitution, microstructure and hardness of laser hardfaced deposits were examined by optical microscope, scanning electron microscope, energy dispersion spectroscopy, x-ray diffraction and Vickers hardness tester. The TS was varied between 300 and $500 \mathrm{~mm} / \mathrm{min}$. The other parameters such as, laser power, powder feed rate, and defocusing distance were kept constant. From this investigation, it is found that the deposit hardness increased from $750 \mathrm{HV}$ to $800 \mathrm{HV}$ with decreasing in TS. The TS increases, bead height decreased and dilution and depth of penetration increased. Due to higher TS the faster cooling rate takes place, it causes the cracking and porosity. Microhardness and wear resistance are slightly improved in the TS of $400 \mathrm{~mm} / \mathrm{min}$. The microstructures of deposit

\footnotetext{
*Corresponding author: S. Gnanasekaran, Centre for Materials Joining \& Research (CEMAJOR), Department of Manufacturing Engineering, Annamalai University, Annamalainagar, Tamil Nadu 608002, India, E-mail: gnanasekaran1947@gmail.com

G. Padmanaban: E-mail: gknaban@rediffmail.com,

V. Balasubramanian: E-mail: visvabalu@yahoo.com, Centre for Materials Joining \& Research (CEMAJOR), Department of

Manufacturing Engineering, Annamalai University,

Annamalainagar, Tamil Nadu 608002, India

Hemant Kumar, Materials Technology Division, Indira Gandhi Centre for Atomic Research (IGCAR), Kalpakkam 603102, Tamil Nadu, India, E-mail: hemant@igcar.gov.in

Shaju K. Albert, Materials Engineering Group (MEG), Indira Gandhi Centre for Atomic Research (IGCAR), Kalpakkam, Tamil Nadu 603102, India, E-mail: shaju@igcar.gov.in
}

layer are composed of Ni-rich carbide, boride and silicide, this are the responsible for higher hardness and better wear resistance.

Keywords: laser hardfacing, austenitic stainless steel, nickel based powder, travel speed, microstructure, wear

\section{Introduction}

Austenitic stainless steel (ASS, $316 \mathrm{LN}$ ) is the major construction material for prototype fast breeder reactor (PFBR). The main vessel, inner vessel, grid plate, and primary piping, etc., whose service temperatures are above $427^{\circ} \mathrm{C}$, are made of 316LN ASS containing 0.06$0.08 \%$ Nitrogen. For primary and secondary piping systems of PFBR, ASS 316LN are preferred due to its corrosion resistance and good creep strength [1]. It is well-known that ASSs have poor wear characteristics during sliding. Their wear rates are typically high and they exhibit a marked tendency to suffer severe damage by galling and seizing. As ASS 316LN material is highly prone to galling and seizing under the sliding contact at high temperature. To avoid the problem of galling, which is an extreme form of adhesive wear, hardfacing of the mating surfaces has been widely used [2].

In comparison to conventional surface-deposition technologies such as spray and fuse or arc-welding processes, laser hardfacing/cladding has distinct advantages including minimal dilution from the base metal, lower heat input and hence less distortion and smaller heat affected zone in the substrate component, fully dense coatings with metallurgical bonding to the substrate, excellent control of the layer thickness and composition, better surface quality and tight dimensional tolerances with higher material usage and little or no after-machining, the possibility of selective and precise deposition on sensitive high-value components, etc $[3,4]$. Up to now, laser hardfacing has not been used as widely as the conventional techniques because of drawbacks such as comparatively high capital cost, 
low deposition rates, and large residual stresses resulting in high cracking susceptibility [5]. The issues of high capital cost and low deposition rates have largely been solved in recent years by technological advances such as the introduction of high power diode laser and high power disk lasers with a beam as wide as 1 inch and integration of inductive heating modules to laser hardfacing heads. For example, with the laser as the only energy source, deposition rates of $9 \mathrm{~kg} / \mathrm{h}$ of Inconel 625 corrosion protective coatings on large cylindrical components are reported. Furthermore, a deposition rate of $14-16 \mathrm{~kg} / \mathrm{h}$ of Inconel 625 can be achieved with the simultaneous application of an $8-\mathrm{kW}$ laser and 12-kW induction power [6].

Although the induction assisted laser hardfacing systems are also reported to greatly reduce the cracking problem of laser clad deposits, cracking is still the biggest materials engineering challenge for a more widespread application of laser hardfacing, especially for high hardness alloys such as Ni-Cr-B-Si-C [3]. Ni-Cr-BSi-C hardfacing alloys are among the most widely used alloys for applications requiring corrosion and wear resistance. These alloys with their low melting point and self-fluxing properties were originally developed for spray and fuse applications. In recent years, laserdeposition technologies were successfully used to produce dense Ni-Cr-B-Si-C coatings with metallurgical bonding to the substrate and superior functional properties [7, 89 9]. Despite the desirable corrosion and wear properties of Ni-Cr-B-Si-C alloys and their potential for many surface coatings, as well as repair and free-form manufacturing applications [3, 10, 11], high cracking propensity poses a serious drawback to their usage in laser-deposition technologies [12].

During the solidification and the subsequent rapid cooling, shrinkage of the melt pool and the constraint of the substrate may produce tensile stresses in the clad layer up to several hundred MPa [3]. When combined with the low ductility of the clad layer, these tensile stresses can surpass the ultimate tensile strength of the deposit and result in a rapid propagation of cracks. In this cracking process, both tensile stresses and ductility of the deposits play a role. Hence, the efforts to solve the cracking problem of laser-deposited coatings have been focused on either reducing the tensile stresses in the hardfaced layers or increasing the ductility of the deposited alloys. The combination of laser cladding and simultaneous induction preheating, which is being increasingly used to deposit crack-free Ni-Cr-B-Si-C coatings [13, 14]. Li et al. studied the influences of processing parameters on forming characterizations during laser hardfacing. They reported that processing parameters are closely related, so would produce intricate effects on the properties of the hardfacing deposit [15]. Zhang et al. reported that effect of processes parameter on bead height, bead width, penetration depth and dilution of laser hardfaced Colmonoy 6 deposits are analyzed. Increasing the travel speed (TS), bead height and bead width decreased however, penetration depth and dilution increased [16].

High rate of cooling (Faster TS) during solidification which is believed to improve the functional properties of the deposits such as hardness. In addition to increase the cooling rate and of course reducing the processing time, higher TS is reported to improve the energy efficiency of the process [17-19]. Due to these benefits, there is a motivation to increase the TS during the laser hardfacing process. On the other hand, hardfacing at higher TSs increases the risk of forming defects, e.g. crack and porosity, in the deposited layers [20, 21]. In this investigation more complete picture about correlation between TS, microhardness and wear resistance of laser hardfaced deposit. Also answer the question of whether faster TS beneficial or not and hence accepting the higher risk of forming defects is compensated by a significant improvement in the hardness and wear resistance of deposit.

\section{Experimental details}

\section{Substrate and powder details}

The chemical composition of the base metal was obtained using a vacuum spectrometer. The chemical composition of the base metal and powder is presented in Tables 1 and 2 . Physical properties of hardfaced powder shown in the

Table 1: Chemical composition (wt \%) of substrate material.

\begin{tabular}{|c|c|c|c|c|c|c|c|c|c|c|c|c|}
\hline \multirow[t]{2}{*}{ AISI 316LN } & C & $\mathrm{Ni}$ & $\mathrm{Cr}$ & Mo & Si & $\mathrm{Mn}$ & $\mathrm{Cu}$ & $\mathrm{Nb}$ & $\mathbf{S}$ & $\mathbf{P}$ & $\mathbf{W}$ & $\mathrm{Fe}$ \\
\hline & 0.020 & 12.55 & 17.27 & 2.35 & 0.29 & 1.69 & 0.047 & 0.02 & 0.027 & 0.026 & 0.03 & Bal \\
\hline
\end{tabular}


Table 2: Chemical composition (wt \%) of hardfaced powder.

\begin{tabular}{rrrrrrrr}
\hline Colmonoy-5 & C & Fe & Cr & Si & B & 0 & Ni \\
\cline { 2 - 8 } & 0.41 & 3.10 & 10.44 & 4.02 & 2.26 & 0.03 & Bal \\
\hline
\end{tabular}

Table 3: Physical properties of hardfaced powder.

\begin{tabular}{lrrr}
\hline $\begin{array}{l}\text { Flow rate } \\
(\mathbf{s e c} / \mathbf{5 0 ~ g )}\end{array}$ & $\begin{array}{r}\text { App. density } \\
\left(\mathrm{g} / \mathrm{cm}^{3)}\right.\end{array}$ & $\begin{array}{r}\text { Hardness } \\
(\text { HRC })\end{array}$ & $\begin{array}{r}\text { Particle size (mesh) } \\
\boldsymbol{\mu m}\end{array}$ \\
\hline 16 & 4.50 & $51-54$ & \pm 45 to 180 \\
\hline
\end{tabular}

Table 3. Rolled plates of $12 \mathrm{~mm}$ thickness has been used as the base material. The substrate was preheated to $450^{\circ} \mathrm{C}$ to relieve the internal stresses and also to reduce the cooling rate to avoid the formation of cracks after deposition. The average thickness of deposit was about 1-2 mm on the stainless steel. Table 4 shows fixing the working range of TS, based on multiple trials the working range has been fixed. After hardfacing, the deposits were cut into small samples for the metallography study. Five $\mathrm{ml}$ Ethanol, $3 \mathrm{ml} \mathrm{HNO}_{3}$ and $10 \mathrm{ml} \mathrm{HF}$ was used to etch the transverse cross-section of the deposit. A Vickers microhardness testing machine (Make: SHIMADZU, Japan; Model: HMV-2T) was employed to measure the hardness across the hardfaced deposit cross section with a load of $0.5 \mathrm{~kg}$ and dwell time of $15 \mathrm{~s}$. Microstructural analysis was carried out using a light optical microscope (OM) (Make: MEIJI, Japan; Model: MIL-7100) incorporated with an image analyzing software (Metal Vision).

Table 4: Macrostructure analysis for fixing the working range of travel speed.

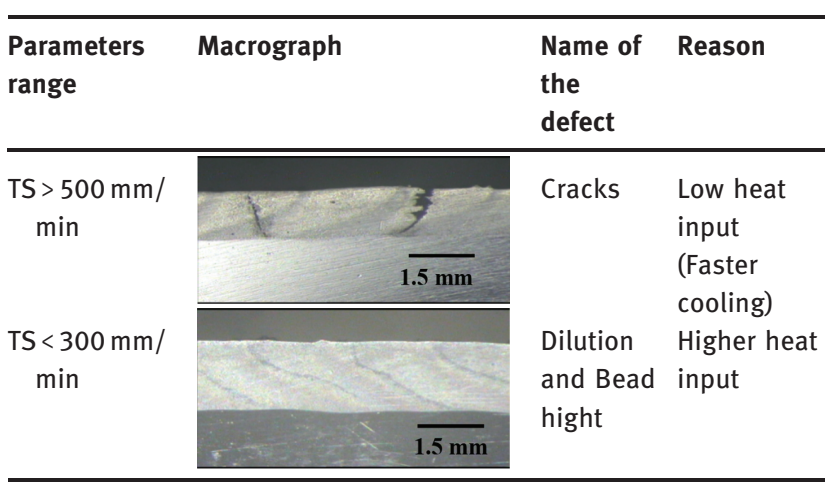

\section{Laser hardfacing setup}

The system for laser hardfacing consists of solid state disc laser Trumpf TruDisk 8002, which emits on wavelength $1030 \mathrm{~nm}$ and maximal available power is $5300 \mathrm{~W}$. The laser radiation is coupled via $600 \mu \mathrm{m}$ optical fiber to Practice coaxial four-way cladding head YC52. The cladding head is equipped with motorized collimator which allows changing of laser spot diameter in the range from 1.26 to $3.37 \mathrm{~mm}$. The hardfacing head is mounted on industrial robot Fanuc M710iC. The pure argon (99.9\%) was used as a powder feeding gas and also as a shielding gas. The laser hardfacing system is on the Figure 1. The experiments were conducted by forming a single layer.

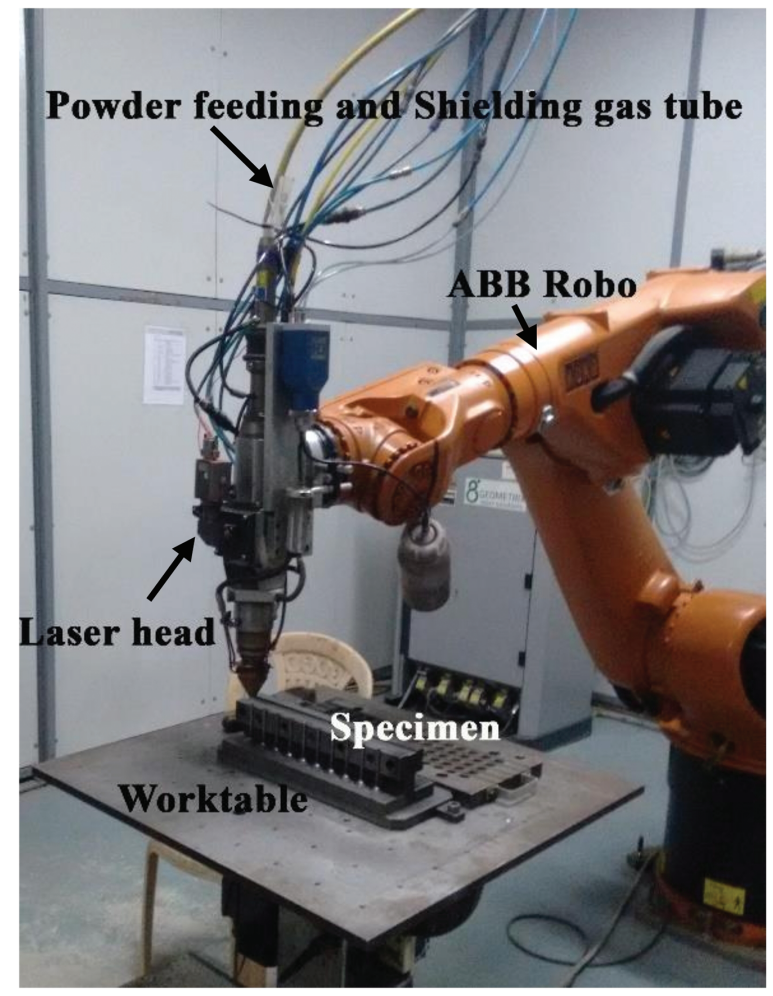

Figure 1: Arrangements of laser hardfacing.

\section{Dilution}

Hardfaced specimens were extracted by sectioning at the middle of the deposit. Metallographic procedures were followed to polish the specimen surface and specimens were etched using $2 \%$ Nital. Bead profile and bead geometries as shown in Figure 2 were visualized and recorded using the scanner at high resolution. Area (\%A and $\% \mathrm{~B}$ ) was calculated using image analyzing software (Metal Vision). Dilution was calculated using the following expression [2]. 


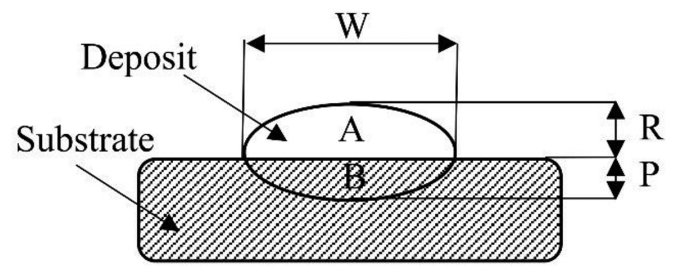

Figure 2: Bead profile and bead geometries.

$$
\text { Dilution }(\%)=\frac{B}{A+B} \times 100 \%
$$

\section{Results and discussions}

\section{Effects of TS on macrostructure, microstructure}

The macrostructure of the hardfaced specimens is shown in the Figures 3 and 4. TS varied between $300 \mathrm{~mm} / \mathrm{min}$, $400 \mathrm{~mm} / \mathrm{min}, 500 \mathrm{~mm} / \mathrm{min}$ and other parameters are kept
Where,

$$
\begin{aligned}
& \text { P - Penetration depth } \\
& \text { R - Reinforcement (Deposit) } \\
& \text { W - Width } \\
& \text { A - Reinforcement area } \\
& \text { B - Penetration Area }
\end{aligned}
$$

in to constant (Table 5). At lower TS $300 \mathrm{~mm} / \mathrm{min}$, bead height higher and dilution, penetration depth is low for the reason that repetitive heating due to slow TS, powder flow is high so bead height increased. Impact of TS on macrostructure, we can see that bead height decrease with increasing the TS, however, penetration depth and dilution increase (Figure 5). In actuality, while expanding the TS, the energy utilized for building up the bead gets less, so the bead height decrease. In any case, in the meantime, the energy for heating the base material becomes much more, thus the penetration depth and dilution increase.

The effects of the TS on the microstructure are shown in Figures 6(a-c). When the TS is $300 \mathrm{~mm} / \mathrm{min}$, coarse dendrites are observed in the deposit layer. When the laser TS is increased to $400 \mathrm{~mm} / \mathrm{min}$, the coarse dendrites
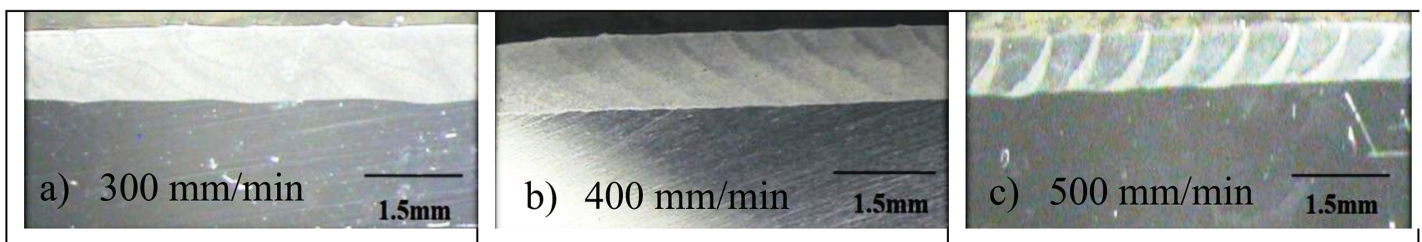

Figure 3: Effect of travel speed on macrostructure.

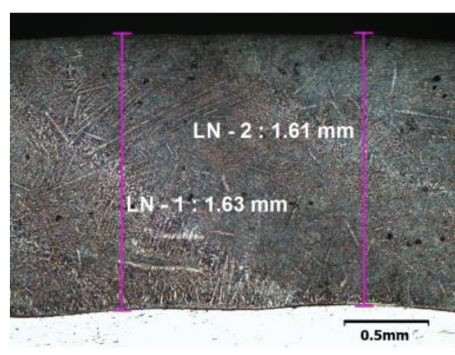

a) $300 \mathrm{~mm} / \mathrm{min}$

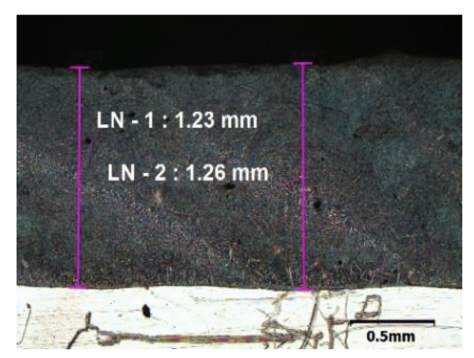

b) $400 \mathrm{~mm} / \mathrm{min}$

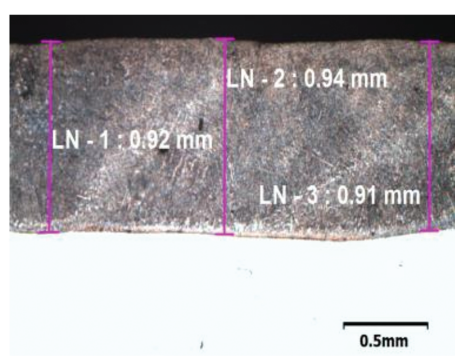

c) $500 \mathrm{~mm} / \mathrm{min}$

Figure 4: Effect of travel speed on deposit thicknesses. 
Table 5: Processes parameter and heat input for travel speed.

\begin{tabular}{lrrrrrr}
\hline $\begin{array}{l}\text { Travel speed } \\
(\mathrm{mm} / \mathrm{min})\end{array}$ & $\begin{array}{r}\text { Laser power } \\
(\mathrm{W})\end{array}$ & $\begin{array}{r}\text { Powder feed rate } \\
(\mathrm{g} / \mathrm{min})\end{array}$ & $\begin{array}{r}\text { Defocusing distance } \\
(\mathrm{mm})\end{array}$ & $\begin{array}{r}\text { Heat input } \\
\mathbf{( J / m m})\end{array}$ & $\begin{array}{r}\text { Specific energy } \\
(\mathrm{E})(\mathbf{k J} / \mathbf{g})\end{array}$ & $\begin{array}{r}\text { Powder density } \\
\left(\mathbf{g} / \mathbf{m m}^{2}\right)\end{array}$ \\
\hline 300 & 1500 & 7 & 27 & 300 & 12.85 & 0.00777 \\
400 & & & & 225 & & 0.00583 \\
500 & & & & 180 & & 0.00466 \\
\hline
\end{tabular}

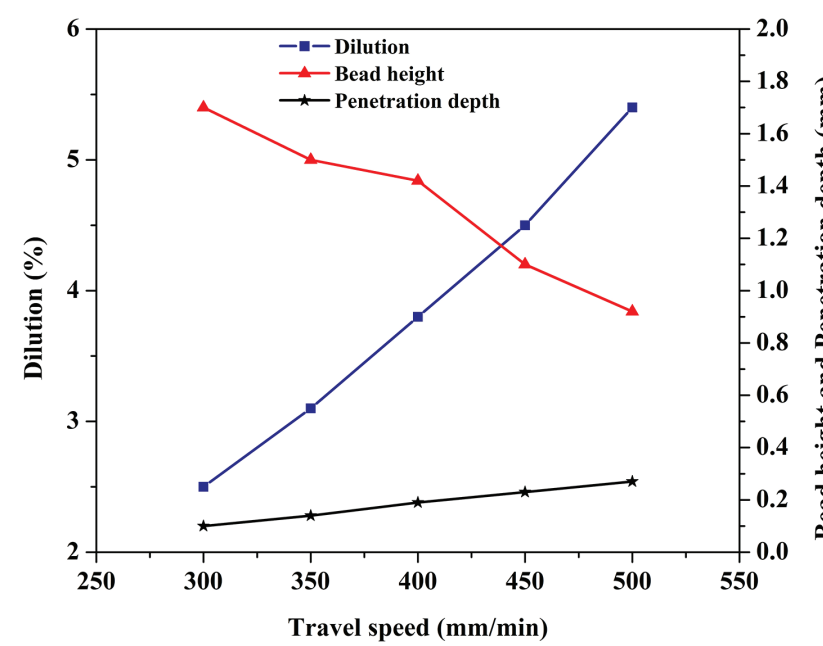

Figure 5: Effects of travel speed on bead height, penetration depth and dilution.

are relatively fine. When laser TS is further increased to $500 \mathrm{~mm} / \mathrm{min}$, the dendrites are finer. So, for low TS, the growth of the $\gamma$-nickel is characterized by coarse columnar dendrites, the phases between the $\gamma$-nickel dendrites are eutectic phases. As the TS increases, the $\gamma$-nickel dendrites become fine. Microstructure of the nickelbased laser hardfaced deposits are directly related to the hardfacing parameters considered, for example, the laser power, powder feed rate, TS and defocusing distance. In the present investigation, laser powder, powder feed rate, and defocusing distance are fixed, so the effects of the TS are examined. The microstructure of the hardfaced samples with TS are related more obviously in terms of specific energy $E_{S}(\mathrm{~kJ} / \mathrm{g})$. Specific energy is defined as energy available per unit mass. $E_{\mathrm{s}}=\mathrm{P} / \mathrm{PFR} \mathrm{kJ} / \mathrm{g}$, where $\mathrm{P}$ is the laser power [22]. Microstructure at each region depends on the cooling rate and temperature gradient. In the laser deposited $\mathrm{Ni}$ based layer, the main solidification structure is characterized by columnar crystals at the bottom and equiaxed crystals on the top surface. Due to the high-temperature gradient (G) and lower solidification rate (V), at the solid-liquid interface, epitaxial growth from the substrate occurs in the bottom area, showing a typical directional solidification characteristic. In the top area of the melt pool, columnar crystals disappear and equiaxed crystals appear due to the local lower $\mathrm{G}$ and higher $\mathrm{V}$ conditions $[22,23]$. Figures $7(\mathrm{a}-\mathrm{d})$ shows that the Scanning electron microstructure of hardfaced samples differs from a cellular to a dendritic morphology with increasing TS, equivalent to decreasing specific energy. This is because low specific energy will lead to a lesser molten-clad mass temperature, which thus brings about a colder substrate. Hence, a higher cooling rate for ensuing the solidification process. Remember that dendritic solidification is promoted by high temperature gradient and lower solidification rate.

Laser deposits consist of three general components: Cr-rich precipitates such as $\mathrm{CrB}, \mathrm{CrC}$, Ni solid solution dendrites, Ni-B-Si binary and ternary eutectic phases including $\mathrm{NiB}, \mathrm{NiSi}$ (Figures 7(a-d)) [24]. Microstructural analysis of the hardfaced deposit in the back scattered image (BSE) mode show two distinct types of precipitates: floret (Eutectics) and grey $\left(\mathrm{Cr}_{23} \mathrm{C}_{7}\right)$. Figure $7(\mathrm{~d})$ represents a BSE image of the microstructure of Colmonoy 5 deposit. Floret and grey precipitates are marked and shown in the Figures $7(\mathrm{c})$ and (d), respectively, while the white matrix is marked in Figure 7(b). The EDS analysis (Figure 8(b)) identifies floret region as $\gamma$ - $(\mathrm{Ni}, \mathrm{Fe}) / \mathrm{Cr}_{7} \mathrm{C}_{3}$ eutectic. As shown in Figure 8(b), the EDS result confirms that the darker blocky region contains Ni solid solution $\gamma$ - (Ni, Fe). The precipitates in the fine lamellar regions are $\mathrm{Ni}_{3} \mathrm{Si}$, and they form the eutectic structure $\gamma-(\mathrm{Ni}, \mathrm{Fe}) / \mathrm{Ni}_{3} \mathrm{Si}$ with the matrix (Figure 7(c)). Liyanage et al. reported the presence of $\mathrm{Ni}_{3} \mathrm{Si}$ in their work [25]. The EDS analysis shows that many chromium boride precipitates are $\mathrm{CrB}$ (black region) around the $\gamma$ - $(\mathrm{Ni}, \mathrm{Fe}) / \mathrm{Cr}_{7} \mathrm{C}_{3}$ eutectic region and some of them connect to the precipitate tips of the floret in shape.

Figure 9 shows XRD analysis of the deposit indicating that the precipitates mainly correspond to the phases 


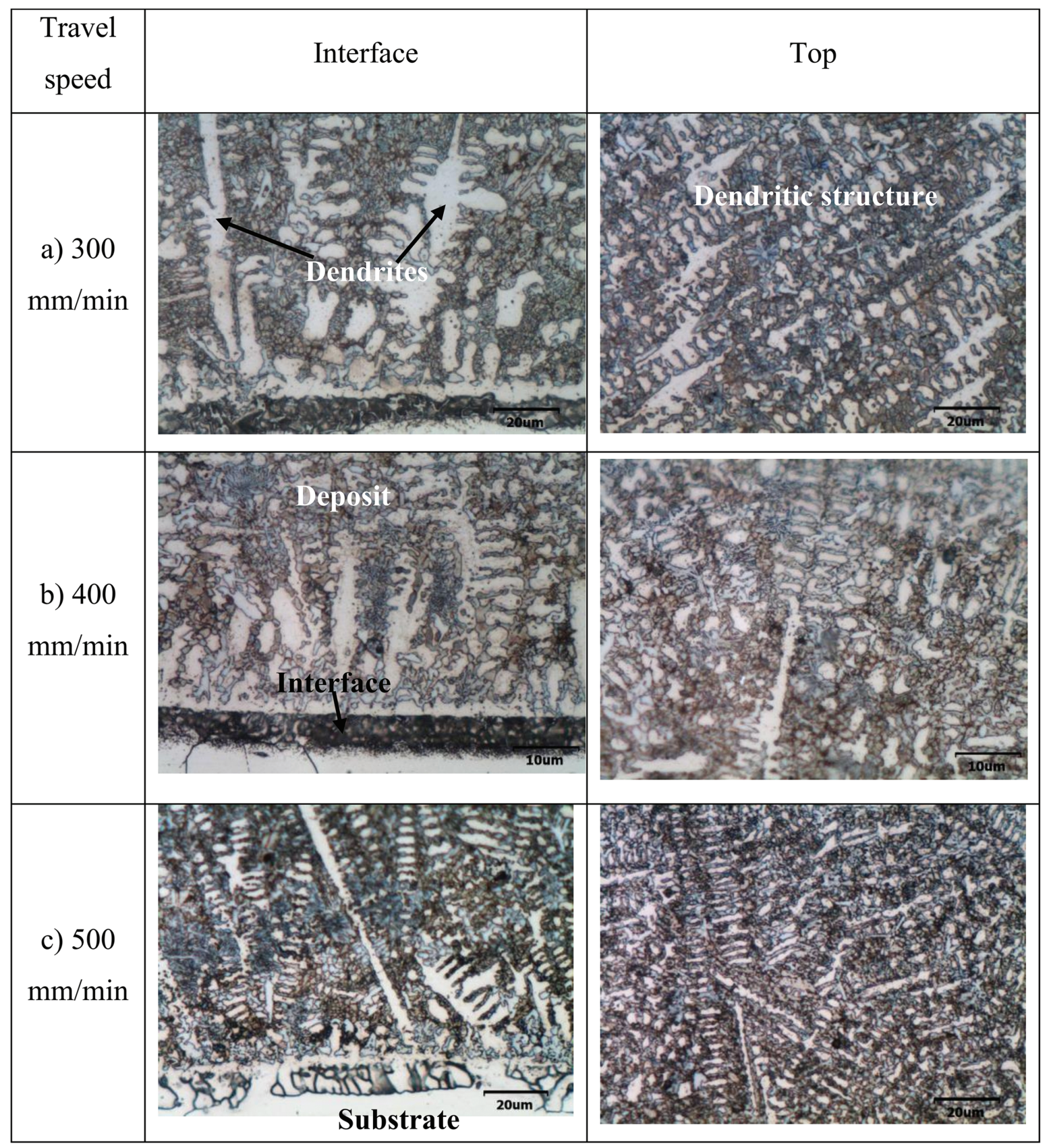

Figure 6: Effect of travel speed on microstructure.

$(\mathrm{Ni}, \mathrm{Fe})_{3} \mathrm{~B}, \mathrm{Ni}_{3} \mathrm{Si}, \mathrm{Cr}_{7} \mathrm{C}_{3}, \mathrm{Cr}_{23} \mathrm{C}_{7}, \mathrm{CrB}$, and $\mathrm{Ni}_{3} \mathrm{~B}$. The fcc $\gamma$-nickel peaks are most prominent [26]. EDS elemental mapping of the deposit is shown in (Figures 10(a-f)). SEM image of the deposit is shown Figure 10(a) and respective elemental maps of chromium, iron, nickel and silicon are shown in Figure 10(b-e). Figure 10(c) shows that the precipitates are rich in chromium and depleted in nickel content. From Figure 10(d), it is evident that the needlelike structure is chromium rich phase. Figures $11(\mathrm{a}-\mathrm{c})$ shows the EDS line scan qualitative compositional profiles of the constituent elements across the substrate-deposit interface of the hardfaced layers. It infers that Fe content observed in the hardfaced deposit is mainly from the substrate material as Colmonoy-5 powder contains minimal Fe content (3.10 wt \% Fe) (Figure 12 (a-c)). This Fe content is used as a metallurgical measure for the dilution of the deposit, and to compare various hardfaced deposits. The amounts of dilution were diverse in all the laser hardfaced deposits, depending upon the TS (refer Figures $12(a, b, c)$ ). The amount of dilution is 

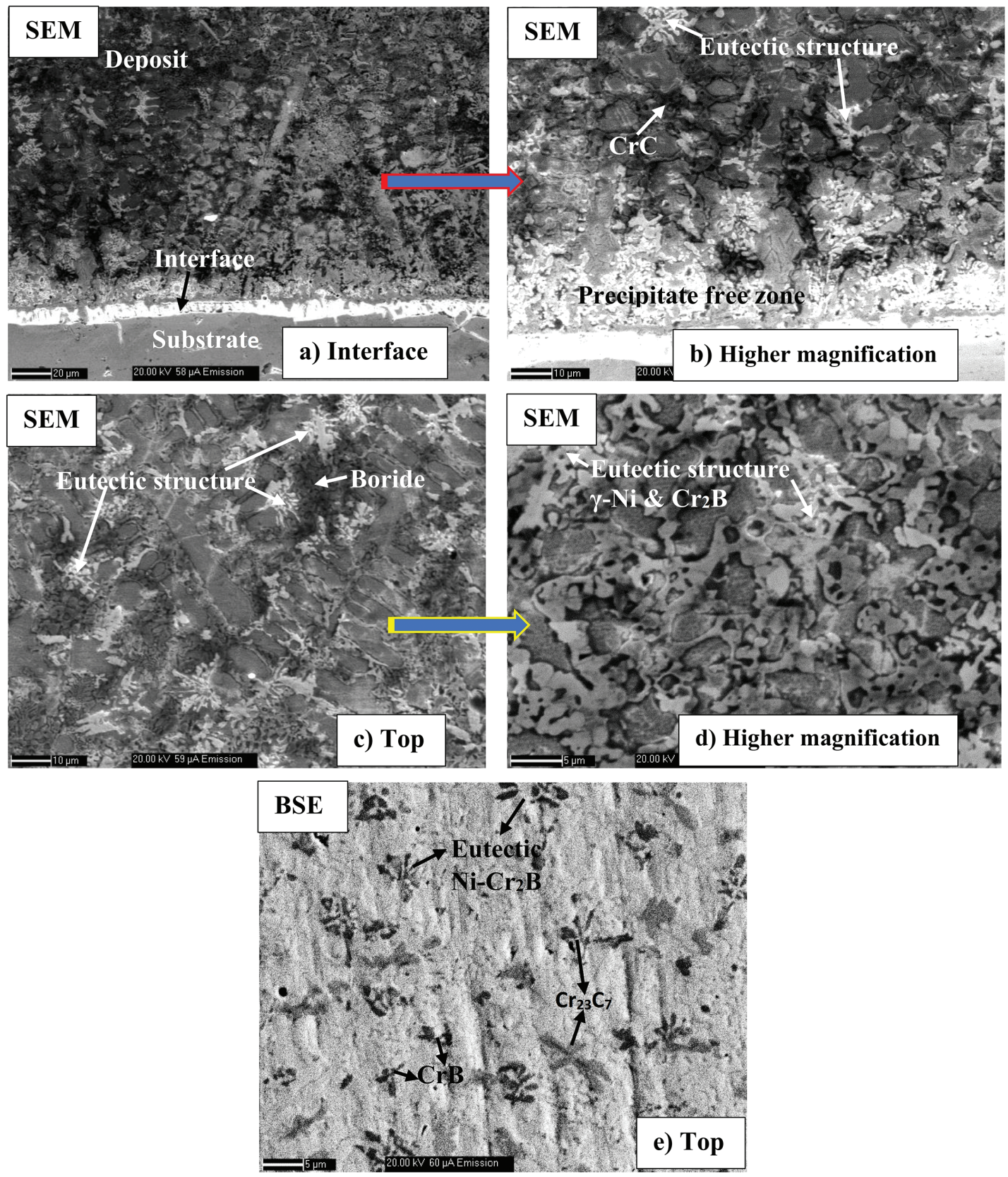

Figure 7: Scanning electron micrograph for various regions.

found to not much variations with increasing TS [27]. The dilution of $\mathrm{Fe}$ in the clad layer deposited at intermediate TS $(400 \mathrm{~mm} / \mathrm{min})$ is inferior, passing from $\sim 10 \mathrm{cps}$ at the substrate/clad interface $(20 \mu \mathrm{m})$ to $\sim 5 \mathrm{cps}$ in the deposit. Moreover, dilution of the substrate from clad material is negligible.

In contrast, the dilution of hardfaced deposit deposited with higher TS $(500 \mathrm{~mm} / \mathrm{min})$ is moderate $(10-12$ cps) near the substrate/deposit interface $(\sim 30-35 \mu \mathrm{m})$ and decreased to $6 \mathrm{cps}$ above the interface, remaining constant along the track. Moderate dilution is recorded in the lower TS of $300 \mathrm{~mm} / \mathrm{min}, \sim 10-14 \mathrm{cps}$, near the interface $(30-40 \mu \mathrm{m})$ of the deposit, which indicate alloying of deposit material with the substrate throughout the deposit. When increasing the TS, the energy used for building up the bead gets less, however, at 

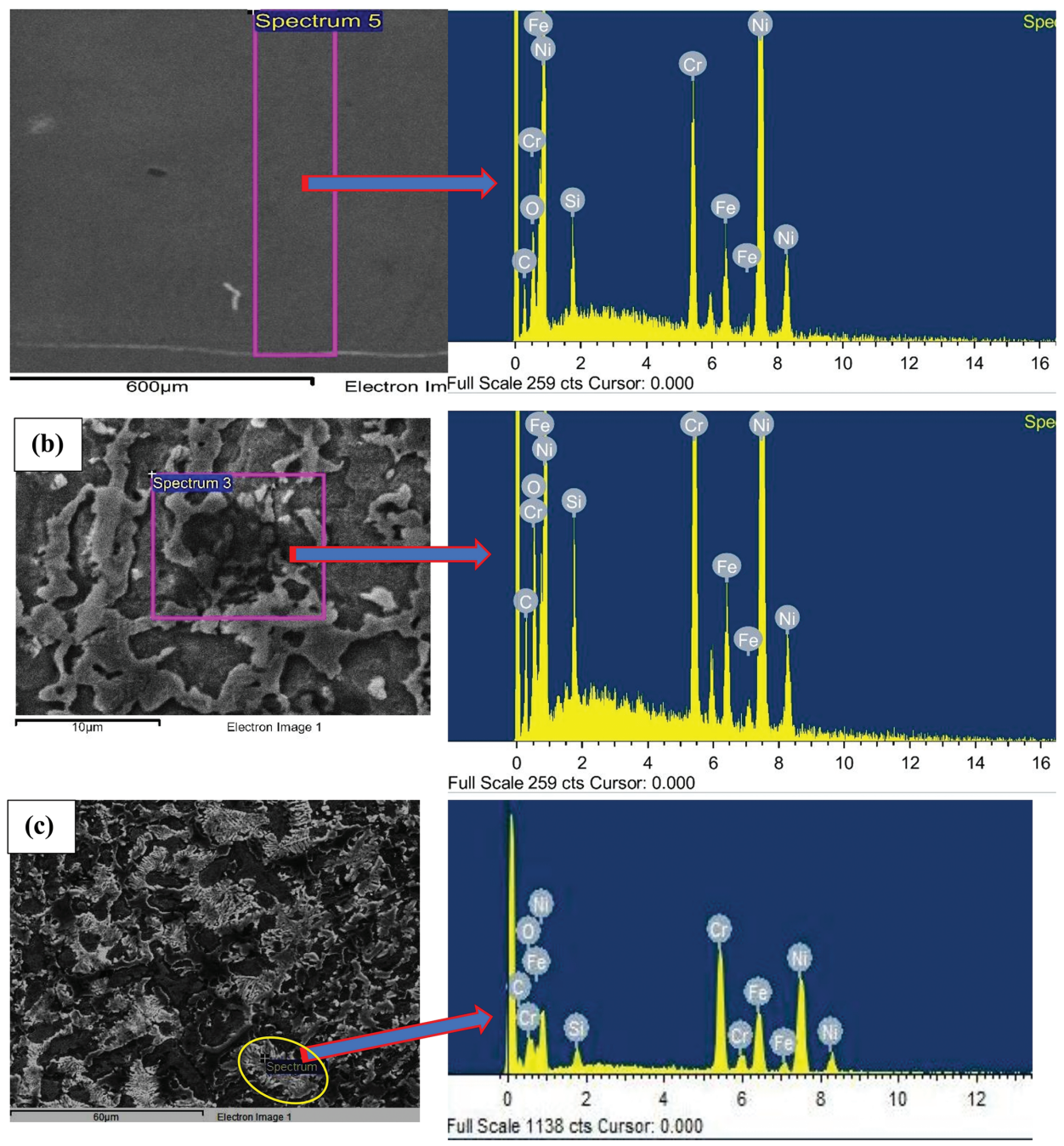

Figure 8: Scanning electron micrograph of the deposit and spot EDS.

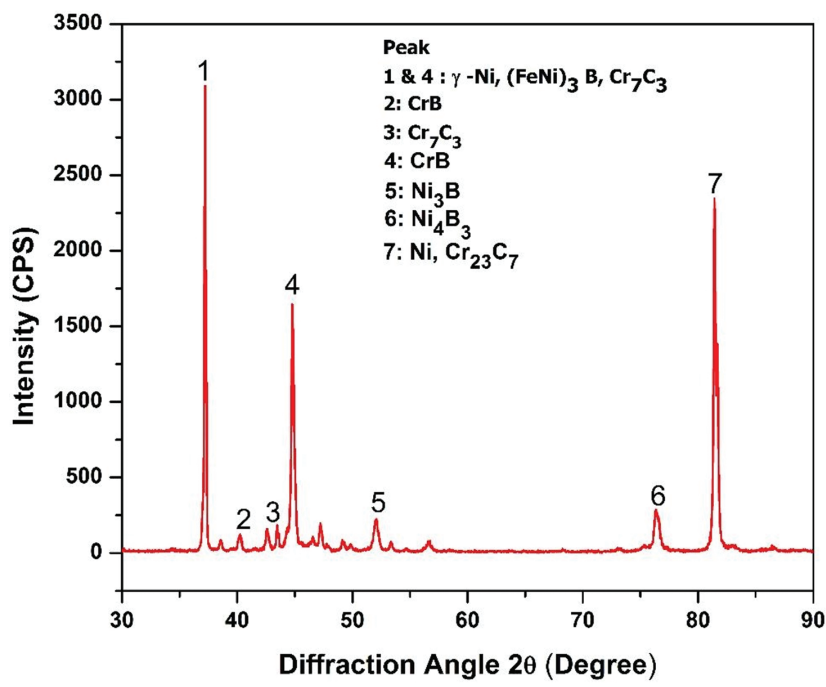

Figure 9: XRD diffraction pattern of the deposit. the same time, the energy for heating the base material becomes much more, thus the penetration depth and dilution increase. Figure 13 shows the $\mathrm{Ni}, \mathrm{Cr}, \mathrm{C}$ and $\mathrm{Si}$ content variations in the substrate/deposit interface and deposits for different TS. It's conformed that absents of $\mathrm{Ni}$ in all $\mathrm{Cr}$ rich regions (refer Figure 13). Similarly $\mathrm{C}$ and Si peaks are absorbed, based on that the precipitates are conformed. The overall Fe content in the deposit varied depending on their dilution with the substrate. EDS analysis also reveals higher Fe content near the interface and decreased further away from interface. In the EDS analysis, it is not possible to quantify the amount of boron in the deposit. Despite the fact that no quantitative results are available for this element, boron seems to be distributed in the track, although it cannot be specified certainly if it is 

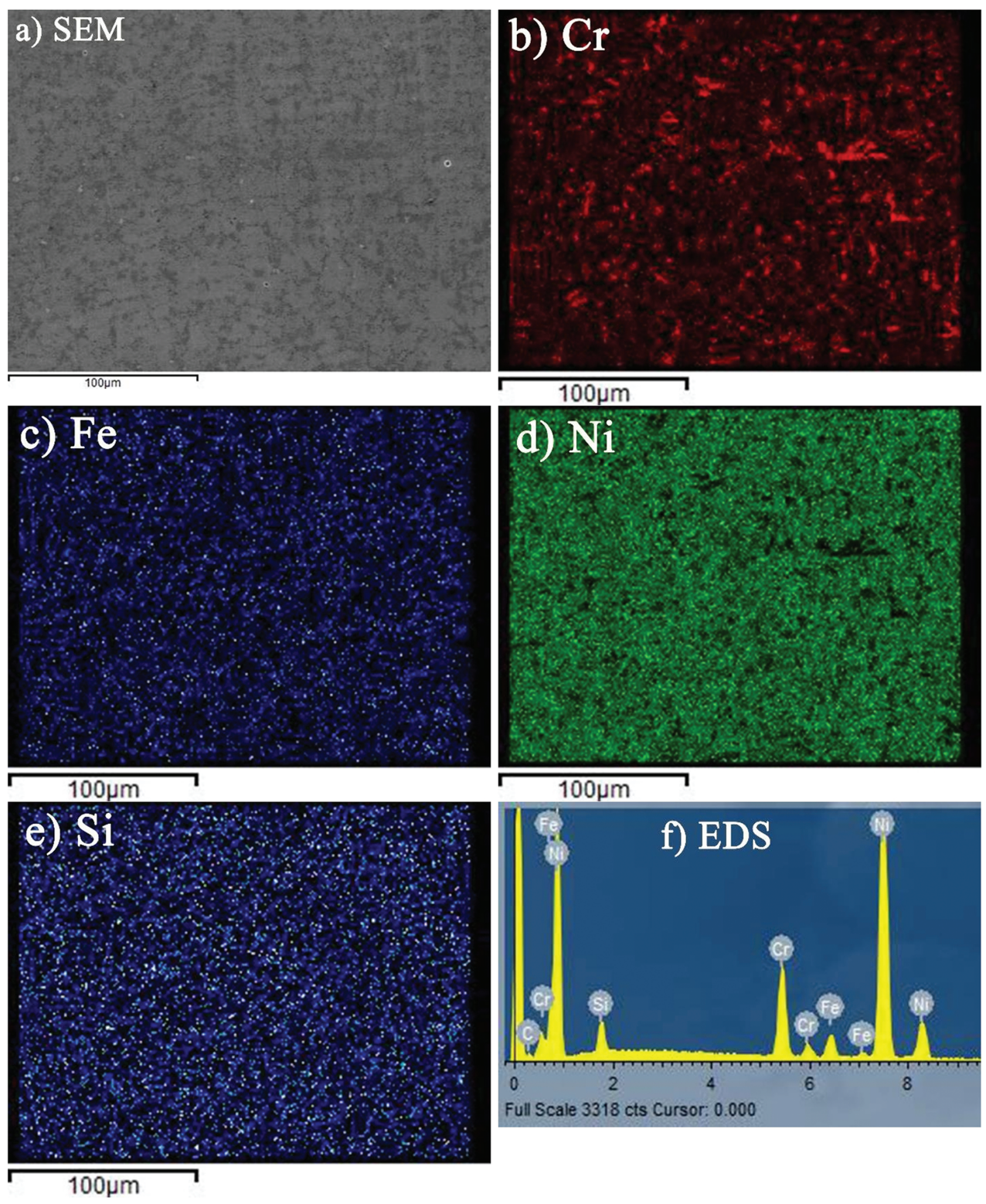

Figure 10: Scanning electron micrograph of the deposit, EDS and elemental mapping.

preferentially located in the solid solution or in the precipitates. The differences between the initial and final compositions may be due to the boron and carbon contents which are impossible to quantify with the analysis technique used. Gurumoorthy et.al. reported that needle-like structure is rich in carbon and floretlike structure is rich in boron [28]. Hemmati et.al. reported that as Fe content increases, borides slowly reduce. Likewise, significantly lower amounts of $\mathrm{Ni}-$ $\mathrm{Si}-\mathrm{B}$ eutectic phases form as a result of Fe pickup. In addition, higher Fe content modified and crushed the precipitation of $\mathrm{CrB}$ at the start and the formation of $\mathrm{Ni}-$
$\mathrm{Si}-\mathrm{B}$ eutectics at the end of the solidification. Dismissal of the strengthening components dropped the hardness of the deposit [29].

\section{Effect of TS on microhardness}

The hardness profile across the deposit, interface and substrate is shown in Figure 14. It can be observed that with the increasing of the distance, the hardness profiles all present increasing trend. It is apparent that the microhardness of the laser hardfacing deposit is much higher 

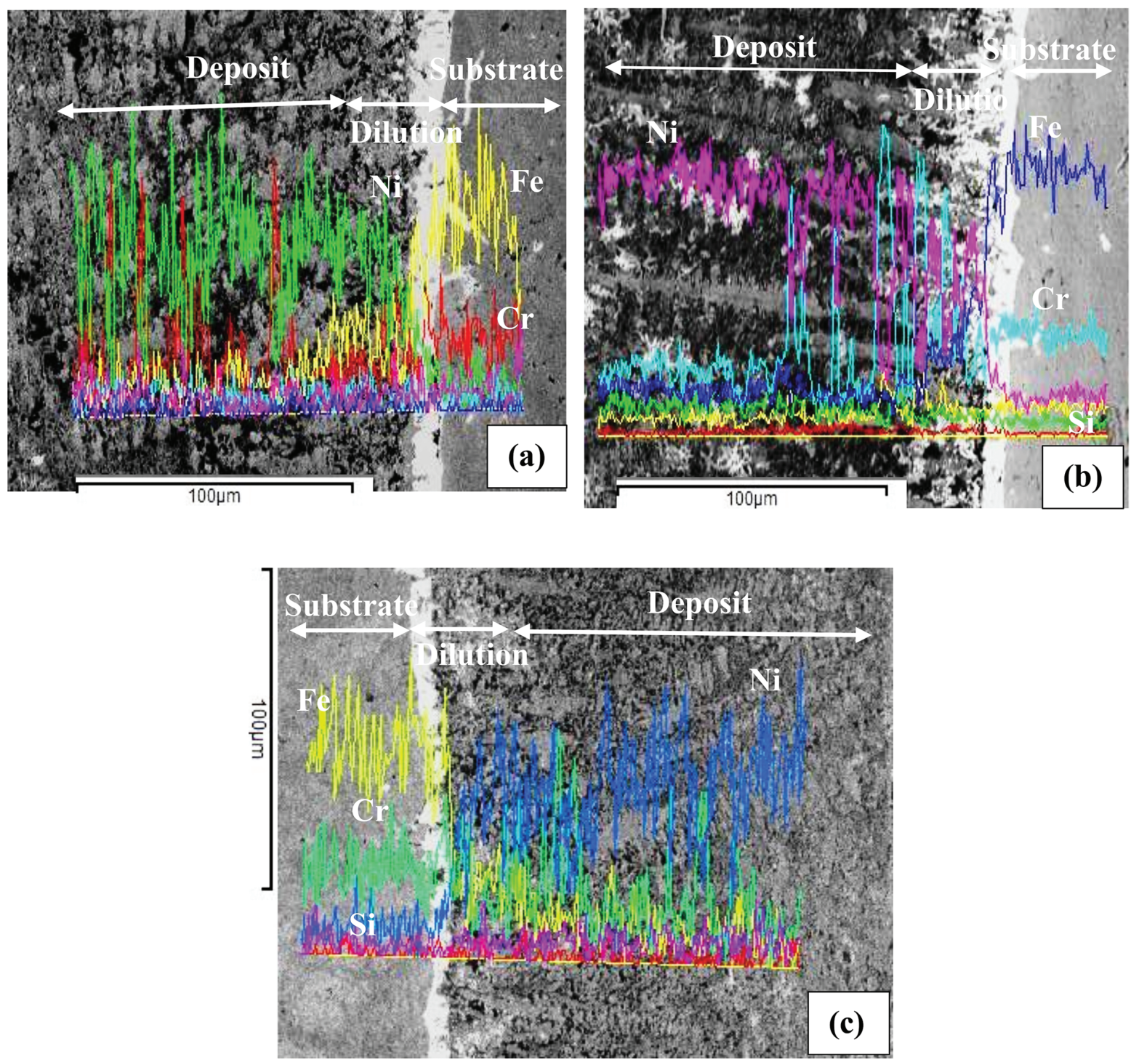

Figure 11: EDS line scan of the constituent elements across substrate/deposit interface. Hardfaced layer deposited at travel speed (a) $300 \mathrm{~mm} / \mathrm{min}$, (b) $400 \mathrm{~mm} / \mathrm{min}$, (c) $500 \mathrm{~mm} / \mathrm{min}$.

than that of the substrate and the interface is significantly improved. In case of microhardness on TS, there is no much different in hardness in all case. It can be seen that clad passes produced at lower TS generally registered higher hardness $(800 \mathrm{HV})$ than those clad at higher TS $(750 \mathrm{HV})$, average base metal hardness is around $230 \mathrm{HV}$. An average of three times increases in the hardness of the Colmonoy 5 deposits are observed compared to the substrate.

The high hardness of these $\mathrm{Ni}$ based hardfacing alloys are due to presence of a large number of boride and carbide precipitates in the matrix [24, 28]. Consequently, the hardness increases as a result of fine microstructure. So, the wear resistance has been related to hardness. The higher hardness of the deposit is attributed to the existence of uniformly distributed carbides and borides precipitates. Similarly, with an increasing TS, the heating temperature of the powder particles decrease and faster cooling rate which leads to cracking.

\section{Effects of TS on dry sliding wear behavior}

Pin-on-disc wear test was conducted as per ASTM G99-05 [30]. Wear test was conducted for substrate and hardfaced deposits. Wear test parameters are shown in 


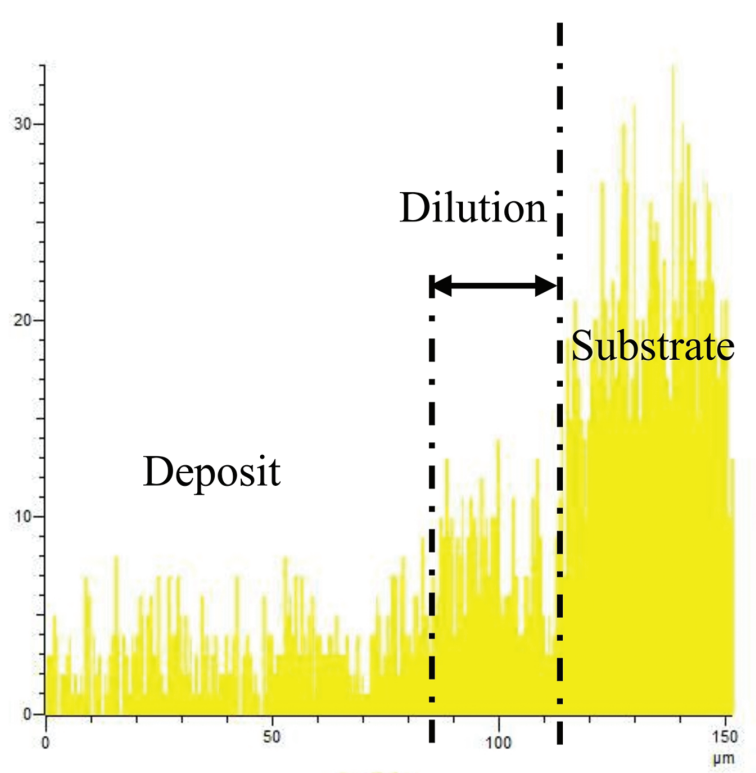

a) $300 \mathrm{~mm} / \mathrm{min}$

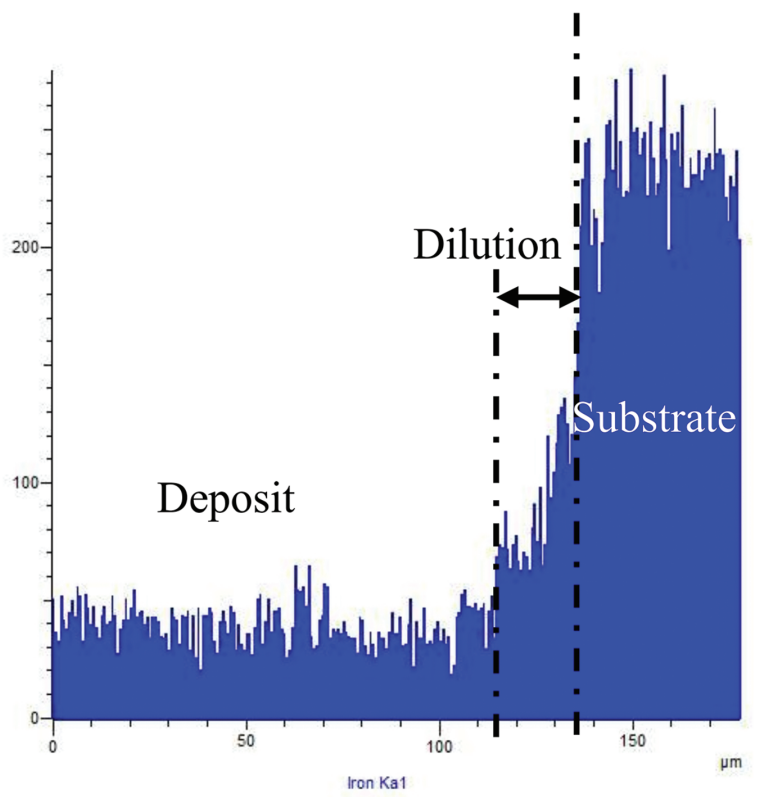

b) $400 \mathrm{~mm} / \mathrm{min}$

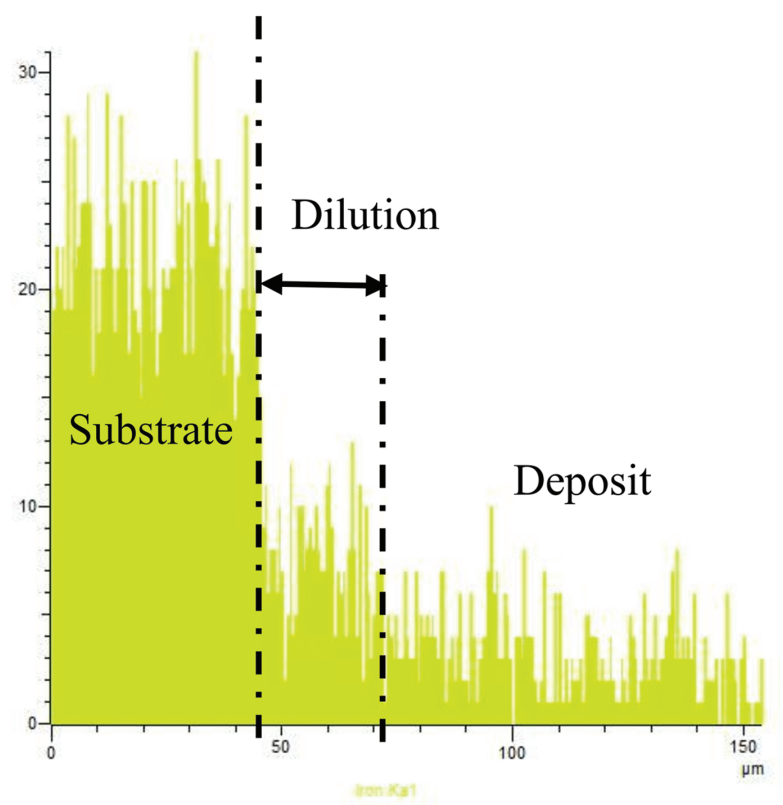

c) $500 \mathrm{~mm} / \mathrm{min}$

Figure 12: Effect of travel speed on Iron (Fe) content.

Table 6. Wear tests were carried out under self-mating condition at room temperature. Maximum weight loss at the initial stage of the wear test is recorded. Weight loss is attributed to the asperities on the wear surface of specimens, which result in the confined contact area of the friction pair than its nominal counterpart. With the test running, the asperities flake off the surface, and the weight loss stabilized [31, 32].
The specimen used for friction and wear tests were made by single-pass laser hardfaced deposits. The coefficient of friction of the specimen with lower TS $(300 \mathrm{~mm} /$ $\mathrm{min}$ ) deposit is consequently lower than that of specimen made with higher TS $(500 \mathrm{~mm} / \mathrm{min})$. Figure 15 displays the coefficient of friction graphs. It shows specimen without laser hardfacing (substrate) is $0.47-0.5$ and laser deposits are $0.142,0.15$, and 0.253 for TS of 300,400 , and $500 \mathrm{~mm} /$ 


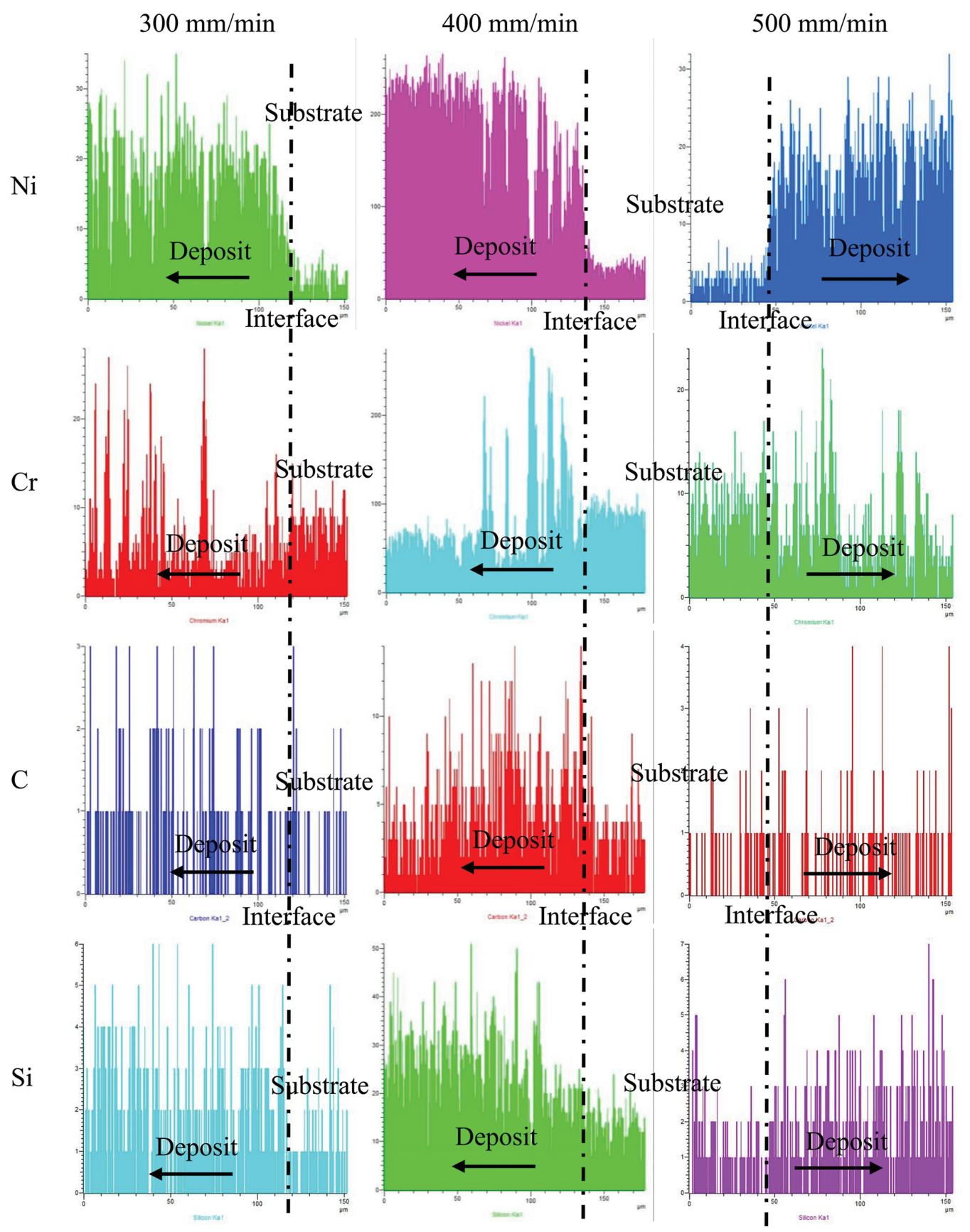

Figure 13: Effect of travel speed on Nickel (Ni), Chromium (Cr), Carbon (C) and Slicon (Si) content.

min, respectively. Increasing the TS, coefficient of friction increased. Compared to higher TS hardfaced deposit, lower TS hardfaced deposit shows little bit higher wear resistance. On the other hand, as the TS increases, less powder is available per unit length of the clad pass (Ref Table 5), so wear resistance is low. Deposit made with lower TS shows better wear resistance compare to higher TS. This enactment is because of the hard phases in the deposit which plays a protective role during the wear test and improves the wear resistance of materials, such as chromium borides (with a hardness of 2575 VHN) and chromium carbides (with a hardness of $1670 \mathrm{VHN}$ ) [33]. The wear resistance of specimen with and without hardfacing (substrate) is shown in Figure 16. The mean weight loss of substrate specimen is $0.62 \mathrm{~g}$, but the mean weight loss of specimen with laser hardfacing is varied between $0.02779,0.02836$ and $0.03472 \mathrm{~g}$ for TS of 300,400 , and $500 \mathrm{~mm} / \mathrm{min}$ correspondingly. Hence, 25-30 times increase in wear resistance of AISI 316LN ASS has been recorded after laser hardfacing of Colmonoy 5 powder. 


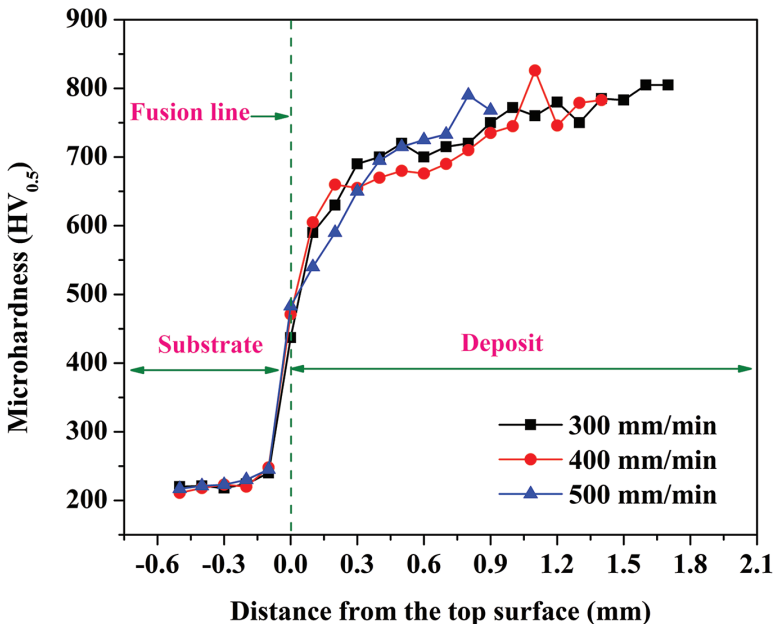

Figure 14: Effects of travel speed on microhardness.

Table 6: Pin on disc wear test parameters.

\begin{tabular}{ll}
\hline Parameters & Values \\
\hline Pin & $\mathrm{D}=10 \mathrm{~mm}, \mathrm{~L}=20 \mathrm{~mm}$ \\
Disc & $\mathrm{D}=160 \mathrm{~mm}, \mathrm{~W}=8 \mathrm{~mm}$ \\
Load & $50 \mathrm{~N}$ \\
Velocity range & $1 \mathrm{~m} / \mathrm{s}$ \\
Sliding distance & $500 \mathrm{~m}$ \\
\hline
\end{tabular}

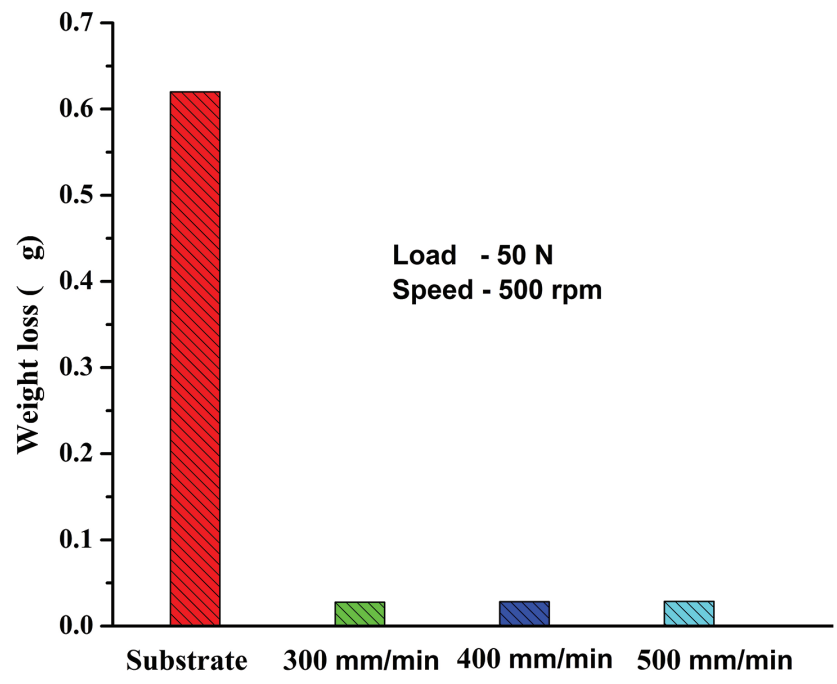

Figure 16: Effects of travel speed on weight loss.

\section{Conclusions}

The laser hardfacing of Colmonoy 5 powder on AISI 316LN ASS was investigating in details, we can get a few conclusions as following:

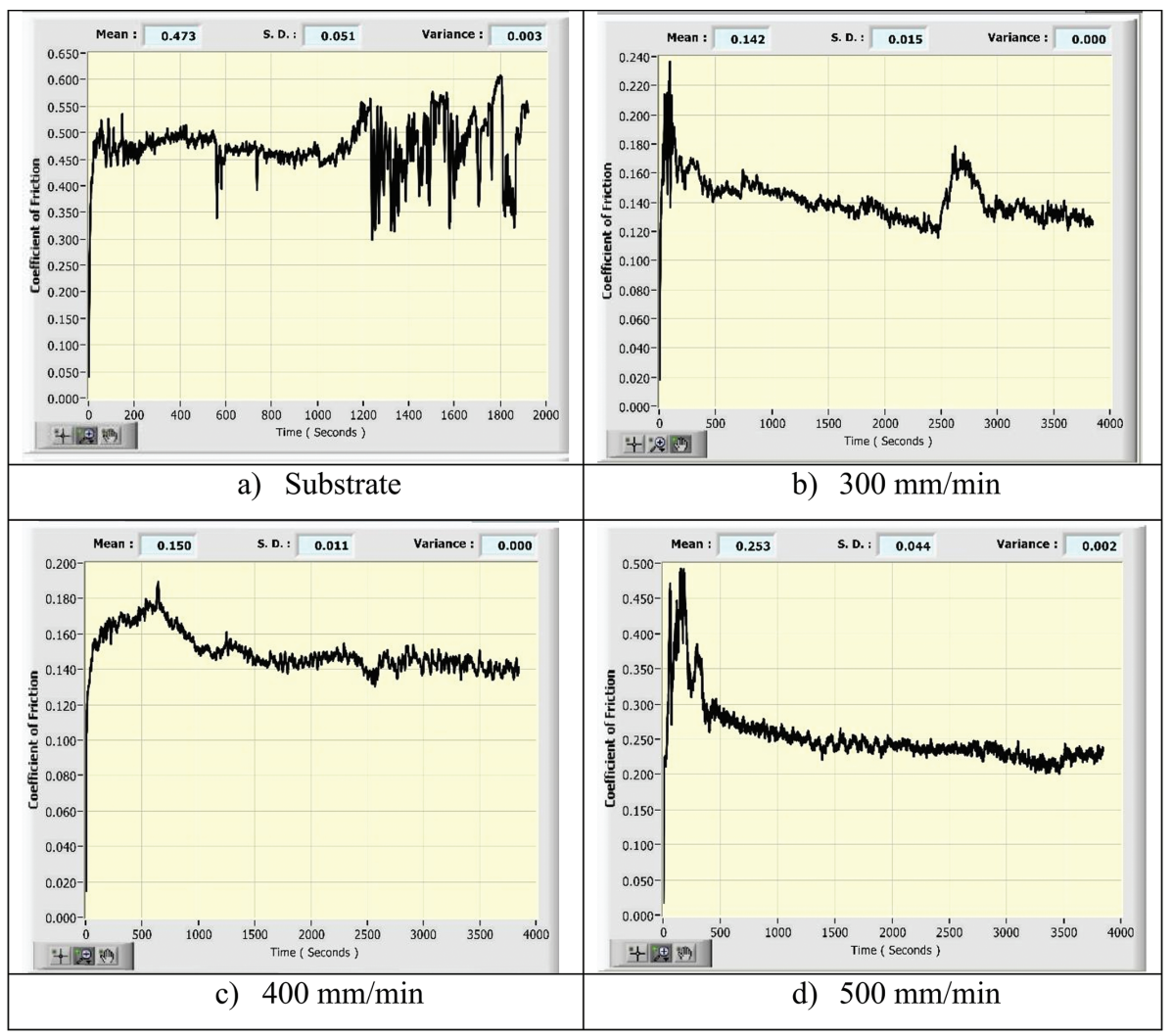

Figure 15: Coefficient of friction graphs for substrate and different travel speed. 
1) The TS bead affect the quality of bead. When the TS increased, bead height and bead width decrease however, penetration depth and dilution slightly increase. Because faster TS ( $500 \mathrm{~mm} / \mathrm{min}$ ) powder density is low, so excess laser power melt the substrate. When the TS is low $(300 \mathrm{~mm} / \mathrm{min})$, coarse dendrites are observed in the deposit layer, because of high heat input.

2) Microstructure of the hardfaced deposit consists of $\mathrm{y}$-Ni solid solution phase as dendrite. The interdendritic constituent comprises $y$-Ni and Ni-rich borides. The microstructure also discloses the presence of a large number of precipitate particles as well as chromium-rich carbides and borides.

3) Laser hardfaced sample exhibited the better wear resistance compared to substrate. This enactment is because of the hard phases in the deposit which plays a protective role throughout the wear test and improves the wear resistance of materials. The effect of TS on wear resistance and microhardness is not as noticeable. But TS is an impartment processes parameter for other point of view like cracking, bead height. The TS of $400 \mathrm{~mm} / \mathrm{min}$ gives better deposit because of moderate dilution, fine dendrites, and moderate bead height.

Acknowledgements: The authors are thankful to UGCDAE consortium for providing financial assistance to carry out this investigation (Project No. CSR-KN/CRS-56/ 2013-14/656 dated 04.09.13). Authors wish to express their sincere thanks to $\mathrm{M} / \mathrm{s}$. Geometrix Laser Solutions Pvt Limited, Tada for laser hardfacing facility. Authors also express their sincere thanks to The Director, IGCAR, Kalpakkam for the base metal supply.

\section{References}

[1] S.L. Mannan, S.C. Chetal, B. Raj and S.B. Bhoje, Materials R\&D for Prototype Fast Breeder Reactor, Edited by S.L. Mannan and M.D. Mathew, Indira Gandhi Centre for Atomic Research, Kalpakkam (2003).

[2] G. Chakraborty, N. Kumar, C.R. Das, S.K. Albert, A.K. Bhaduri, S. Dash and A.K. Tyagi, Surf. Coat. Technol., 244 (2014) 180-188.

[3] K.P. Cooper, Laser surface processing in ASM Handbook, 10th Edition, Vol. 18, Friction, Lubrication, and Wear Technology, Edited by George E. Totten, ASM International (1992), pp. 861-872.

[4] J.T.M. De Hosson, V. Ocelık, U.O.B. De Oliveira and D.I. Vainchtein, Int. J. Mater. Res., 100 (2009) 1343-1360.

[5] Y. Huang and X. Zeng, Appl. Surf. Sci., 256 (2010) 5985-5992.
[6] E. Beyer, New Industrial Systems \& Concepts for Highest Laser Cladding Efficiency. http://www.lia.org/blog/2011/05/high-per formance-laser-cladding.

[7] A. Conde, F. Zubiri and J. De Damborenea, Sci. Eng. A., 334 (2002) 233-238.

[8] J.M. Miguel, J.M. Guilemany and S. Vizcaino, Tribol. Int., 36 (2003) 181-187.

[9] E. Ferna`Ndez, M. Cadenas, R. Gonza`Lez, C. Navas, R. Ferna -Ndez and J. De Damborenea, Wear., 259 (2005) 870-875.

[10] C.P. Paul, A. Jain, P. Ganesh, J. Negi and A.K. Nath, Opt. Lasers Eng., 44 (2006) 1096-1109.

[11] A. Angelastro, S.L. Campanelli and A.D. Ludovico, Adv. Mater. Res., 83-86 (2009) 842-849.

[12] D. Wang, E. Liang, M. Chao and B. Yuan, Surf. Coat. Technol., 202 (2008) 1371-1378.

[13] S. Zhou, X. Dai and H. Zheng, Opt. Laser Technol., 43 (2011) 613-621.

[14] Y. Huang, X. Zeng, Q. Hu and S. Zhou, Appl. Surf. Sci., 255 (2009) 3940-3945.

[15] Y.M. Li, H.O. Yang, X. Lin, W.D. Huang, J.G. Li and Y.H. Zhou, Mater. Sci. Eng. A., 360 (2003) 18-25.

[16] H. Zhang, Y. Shi, M. Kutsuna and G.J. Xu, Nucl. Eng. Des., 240 (2010) 2691-2696.

[17] K. Partes, T. Seefeld, G. Sepold and F. Vollertsen, High efficiency laser cladding at elevated processing speed, in: 24th ICALEO Congress Proceedings, LIA, Miami, FL., 2005: pp. 621-628.

[18] K. Partes, G. Sepold and J. Mater, Process. Technol., 195 (2008) 27-33.

[19] K. Partes, Surf. Coat. Technol., 204 (2009) 366-371.

[20] I. Hemmati, Laser-Deposited Metallic Coatings: Processing, Characterization, Alloy Development, Ph.D Thesis, University of Groningen, 2013.

[21] S. Gnanasekaran, G. Padmanaban, V. Balasubramanian, H. Kumar and S.K. Albert, J Mech Behav Mater., 26 (2017) 113-126.

[22] L.C. Lim, Q. Ming and Z.D. Chen, Surf. Coatings Technol., 106 (1998) 183-192.

[23] Majumdar J. Dutta and I. Manna, Laser-Assisted Fabrication of Materials, Salmon Tower Building, New York City, United States: Springer Series in Materials Science, 161 (2012).

[24] S. Gnanasekaran, G. Padmanaban, V. Balasubramanian and L. Manuf, Mater. Process., 4 (2017) 178-192.

[25] T. Liyanage, G. Fisher and A.P. Gerlich, Surf. Coatings Technol., 205 (2010) 759-765.

[26] Powder diffraction File: PDF-2 database (computer file), JCPDS International Centre for diffraction Data, Newton Square, PA, 1994.

[27] Q. Ming, L.C. Lim and Z.D. Chenc, Surf. Coatings Technol., 106 (1998) 174-182.

[28] K. Gurumoorthy, M. Kamaraj, K.P. Rao, A.S. Rao and S. Venugopal, Mater. Sci. Eng. A., 456 (2007) 11-19.

[29] I. Hemmati, V. Ocelik and J.T.M. De Hosson, Mater. Lett., 84 (2012) 69-72.

[30] ASTM G 99 - 04, Standard Test Method for Wear Testing with a Pin-on-Disk Apparatus, ASTM International, West Conshohocken, PA, (2016), www.astm.org.

[31] ASM Metal Handbook, ASM International, Materials Park, $\mathrm{OH}$ (1993) Vol. 6 9th 794-795.

[32] H. Ocken, Surf. Coatings Technol., 76-77 (1995) 456-461.

[33] C. Sudha, P. Shankar, R.V.S. Rao, R. Thirumurugesan, M. Vijayalakshmi and B. Raj, Surf. Coatings Technol., 202 (2008) 2103-2112. 